\title{
Emotion-Involved Semantic Processing and L2 Vocabulary Memory: A Micro-Level Emotion Manifesto
}

\author{
Yu Kanazawa ${ }^{\mathrm{a}, \mathrm{b}}$ \\ ${ }^{a}$ Otemon Gakuin University; ${ }^{b}$ Kwansei Gakuin University \\ doi: http://dx.doi.org/10.7820/vli.v06.2.Kanazawa
}

\section{Introduction: Affective Turn in SLA}

Emotion is a pervasive phenomenon whose pivotal impacts on cognition have been proposed and increasingly acknowledged (e.g., operator effect and "(de-)energizing" effect; cf. Ciompi \& Panksepp, 2005; Damasio, 2003; LeDoux, 2012). In accordance with this, second language acquisition (SLA) studies have recently seen an "affective turn" (Pavlenko, 2013) and several theories have been proposed and studies conducted concerning the effect of affect in SLA from such perspectives as motivation (Dörnyei \& Ushioda, 2011), foreign language anxiety/ enjoyment (Dewaele \& MacIntyre, 2016), Directed Motivational Currents (Dörnyei, Henry, \& Muir, 2016), and emotional intelligence (Gregersen \& MacIntyre, 2017; Kanazawa, 2016b).

\section{From Macro-Level Emotion to Micro-Level Emotion}

Many of the previous studies on emotion and SLA, however, can be regarded as having a common tendency. As is seen in Garrison, Anderson, and Archer's (1999) brilliant attempt to code community of inquiry, emotional aspects have been regarded as subjective and social elements, which are independent from objective and cognitive elements. This separation has also been the dominant case in research methodology. As King and Mackey (2016) expound, the traditional view of the qualitative scientific method is "the idea that researchers strive to the extent possible to eliminate personal biases, a priori commitments, and emotional involvement" (p. 218) while emotional and contextual constraints on language learning have exclusively been investigated by "anthropologically oriented researchers" (p. 222). Correspondingly, emotion research in SLA tends to avoid cognitive psychological experimental studies in favor of qualitative studies such as narrative analysis and discursive approaches, which have their own self-reportable phenomenological benefits (cf. Miyahara, 2015; Prior \& Kasper, 2016). Although the distinction between subjective self-conscious emotion as an intervening social factor and cognition as the objective intellectual outcome is operationally effective and understandable, it is important to remember that in a microscopic view, emotion is not only related to cognition but also actively and organically "energizing" cognition, moment by moment, and vice versa (Bergson, 1896/1911; Peirce, 1894/1931; Whitehead, 1929/1978). The author would like to propose that the effect 
of emotion on L2 learning should be considered not only from those macro-level self-conscious socio-psychological aspects but also in terms of the micro-level emotion involvement of each here-and-now subtle subconscious cognitive process. Correspondingly, there should be a larger number of serious quantitative studies of micro emotion in SLA utilizing cognitive psychological methodology.

\section{Micro-Level Emotion}

Kanazawa (2016a) investigated whether the emotional attributes of words (i.e., lexical emotional valence) had any impact on L2 memory in an empirical study. It was discovered that micro-level positive valence-facilitated L2 lexical memory without deliberate efforts being made to remember target words. Lexical valence per se, however, is a passive static lexical attribute, whereas what is needed for a better theoretical contribution to SLA is an understanding of how such a micro-level emotion can contribute to the acquisition of new language in an active dynamic manner. The empirical studies reviewed in the present paper concern the effect of micro-level emotion on the active dynamic side of lexical memory formation (i.e., input processing), aiming at extending the scope of micro-level emotion perspectives.

\section{Emotion-Involved Processing}

It has been proposed that not only quantity but also quality of input processing matters in memory formation. According to the influential Levels-of-Processing framework (LOP; Craik \& Lockhart, 1972), deep/semantic processing yields stronger memory traces than shallow/perceptual processing. Although LOP provides a valuable perspective, it is also a model that has been much criticized and disputed (e.g., Barcroft, 2015 [for L2]; Morris, Bransford, \& Franks, 1977 [for L1]). One of the problems of the original LOP is that the variety in the same level of processing is not theorized. It has been empirically shown that different modes of shallow/perceptual processing result in different levels of lexical retention even with the same processing depth (Kanazawa, 2015). It is likewise probable that different modes of deep/semantic processing result in different levels of lexical retention. According to Nation (2015), the quality of processing for successful vocabulary acquisition is determined most crucially by how elaborate the processing is. Judging from previous findings and models in L2 processing (e.g., Schütze, 2017; Sharwood Smith \& Truscott, 2014), it is expected that semantic processing will become more mnemonically effective when micro-level emotion is involved (i.e., emotional elaboration; emotion-involved processing).

\section{Purpose}

The purpose of the experiments was to examine whether emotion-involved semantic processing (EmInvSemProc) results in better incidental L2 memory performance compared to other types of semantic processing (viz., a lexical decision task [LDT] for Experiment A and an imageability judgment task [IJT] for Experiment B). 


\section{Experiment $\mathrm{A}$}

Experiment A was conducted in a laboratory setting. Thirty-six Japanese L2 users of English participated in the experiment. The target stimuli were selected from the proto-ANEW-JLE wordlist, in which words with high BNC frequency and high familiarity scores were selected and the valence scores for each item were rated by Japanese learners of English (Kanazawa, 2016a). The study session was followed by a test session. The study session consisted of two tasks: a valence judgment task (VJT) and an LDT. The VJT was a task in which participants were instructed to "feel" the meaning of each presented word and judge whether it had a positive or negative meaning. The LDT was a task in which participants were instructed to "think about" the meaning of each presented word and judge whether it was a word or a nonword. The VJT employs EmInvSemProc whereas the LDT involved non-emotional semantic processing. The trials were randomized each time the program was run. The order of the two tasks, the couplings of target words (48 positive words and 48 negative words) and task types were counterbalanced between participants.

The test session consisted of two tasks: a free recall memory test and a recognition memory test, both of which were conducted under the incidental learning paradigm. Participants were instructed to recall as many words or recognize words as accurately as possible during the tests. The numbers of correct responses for both memory tests and correct response reaction times (RTs) for the recognition test (dependent variables) were calculated according to (1) processing mode and (2) valence (independent variables). ${ }^{1}$ The experimental procedure abides by the APA Ethics Code (Article 8.02; informed consent to research; American Psychological Association, 2010).

It was revealed that words which were encoded under EmInvSemProc had significant facilitatory benefits for recall memory $(F[1,24]=36.01, p=0.00$, partial $\left.\eta^{2}=0.60\right)$, recognition memory $\left(F[1,35]=15.16, p=0.00\right.$, partial $\left.\eta^{2}=0.30\right)$, and recognition speed $\left(F[1,35]=5.41, p=0.03\right.$, partial $\left.\eta^{2}=0.13\right)$. The findings supported the hypothesis that emotion involvement in semantic processing is more effective in making strong memory traces than non-EmInvSemProc.

\section{Experiment B}

Experiment B was conducted in a university classroom setting in order to ensure higher ecological validity (cf. van Lier, 2004). Thirty Japanese L2 users of English were the target of the study. There were 8 words per unit in 4 units of a textbook, for a total of 32 new words, all of which were unknown to the students. They were subdivided into two groups of 16 words. No statistically significant difference was found for the following lexical attributes between the groups: mean letter length, mean syllable length, mean valence score, and mean BNC frequency. Study tasks were conducted on a university e-learning platform, accessible either on a computer or on a smartphone, as pre-class preparation. There were two study tasks: a VJT and an IJT. The VJT was a task in which participants were instructed to "feel" the meaning of each word and judge its valence on a 4-point Likert Scale. The IJT was a task in which participants were instructed to "imagine" the meaning of each word and judge its imageability on a 4-point Likert Scale. The VJT again employed EmInvSemProc, whereas the IJT required 
non-emotional semantic processing. The IJT was selected as the non-emotional semantic processing tool for the following reasons: (1) it is procedurally similar to the VJT, (2) it shares the same Involvement Load Index (Laufer \& Hulstijn, 2001) as the VJT (Table 1), (3) "Imaging"-involvement is known to play a facilitatory role in L2 lexical acquisition (Nation \& Webb, 2011, p. 10), and (4) imageability is one of the influential factors in vocabulary learning (Schmitt, 2010, p. 53). In terms of Technique Feature Analysis (TFA) criteria (Nation \& Webb, 2011), it was expected that the VJT, whose TFA score was six, would be less effective than the IJT, whose score was seven (Table 2). ${ }^{2}$

Table 1. Two Tasks and Their Involvement Load Indices (Laufer \& Hulstijn, 2001)

\begin{tabular}{lcc}
\hline & VJT & IJT \\
\hline Need & $1(+)$ & $1(+)$ \\
Search & $0(-)$ & $0(-)$ \\
Evaluation & $1(+)$ & $1(+)$ \\
Total score (Involvement Load Index) & 2 & 2 \\
\hline
\end{tabular}

Note. VJT, valence judgment task; IJT, imageability judgment task.

Table 2. Two Tasks and Their Technique Feature Scores (Nation \& Webb, 2011)

\begin{tabular}{|c|c|c|}
\hline & VJT & IJT \\
\hline \multicolumn{3}{|l|}{ Motivation } \\
\hline [No. 1] Is there a clear vocabulary learning goal? & 1 & 1 \\
\hline [No. 2] Does the activity motivate learning? & 1 & 1 \\
\hline [No. 3] Do the learners select the words? & 0 & 0 \\
\hline \multicolumn{3}{|l|}{ Noticing } \\
\hline [No. 4] Does the activity focus attention on the target words? & 1 & 1 \\
\hline [No. 5] Does the activity raise awareness of new vocabulary learning? & 1 & 1 \\
\hline [No. 6] Does the activity involve negotiation? & 0 & 0 \\
\hline \multicolumn{3}{|l|}{ Retrieval } \\
\hline [No. 7] Does the activity involve retrieval of the word? & 0 & 0 \\
\hline [No. 8] Is it productive retrieval? & 0 & 0 \\
\hline [No. 9] Is it recall? & 0 & 0 \\
\hline [No. 10] Are there multiple retrievals of each word? & 0 & 0 \\
\hline [No. 11] Is there spacing between retrievals? & 0 & 0 \\
\hline \multicolumn{3}{|l|}{ Generation } \\
\hline [No. 12] Does the activity involve generative use? & 0 & 0 \\
\hline [No. 13] Is it productive? & 0 & 0 \\
\hline [No. 14] Is there a marked change that involves the use of other words? & 0 & 0 \\
\hline \multicolumn{3}{|l|}{ Retention } \\
\hline [No. 15] Does the activity ensure successful linking of form and meaning? & 1 & 1 \\
\hline [No. 16] Does the activity involve instantiation? & 0 & 0 \\
\hline [No. 17] Does the activity involve imaging? & 0 & 1 \\
\hline [No. 18] Does the activity avoid interference? & 1 & 1 \\
\hline Total score (Technique Feature Analysis) & 6 & 7 \\
\hline
\end{tabular}

Note. VJT, valence judgment task; IJT, imageability judgment task. 
The tests consisted of two tasks: a free recall memory test and an L2-L1 matching test, which were conducted under the semi-incidental and intentional learning paradigms, respectively. Participants were instructed to recall and write the correct spelling of the new words (a voluntary test) or to match the English words with the correct translational equivalences (a compulsory test). The experimental procedure abides by the APA Ethics Code (Article 8.05; the study of normal educational practices, curricula, or classroom management methods conducted in educational settings; American Psychological Association, 2010).

Due to the high rates of incorrect or irrelevant answers in the voluntary recall test, only data whose recall accuracy were at least $90 \%$ were targeted for analysis. The Wilcoxon signed-ranks test indicated that items which were encoded under EmInvSemProc had significant facilitatory benefits over non-emotional semantic processing for recall memory $(Z=-2.06, p<0.05, r=-0.69)$, which corresponds to the hypothesis (Figure 1). No significant difference was detected, however, for the matching test since all participants scored 100\% correct (ceiling effect), which was caused by lack of task difficulty and the nature of the task as an intentional learning exercise.

\section{Discussion and Implication}

EmInvSemProc, although applied with little pedagogical contrivance, was found to be more cognitively facilitatory in the learning of known L2 words (Experiment A) and the acquisition of unknown L2 words (Experiment B) than non -emotional semantic processing. It can be concluded that increasing micro-level subconscious emotion facilitates retentional cognition in L2 lexical learning and acquisition.

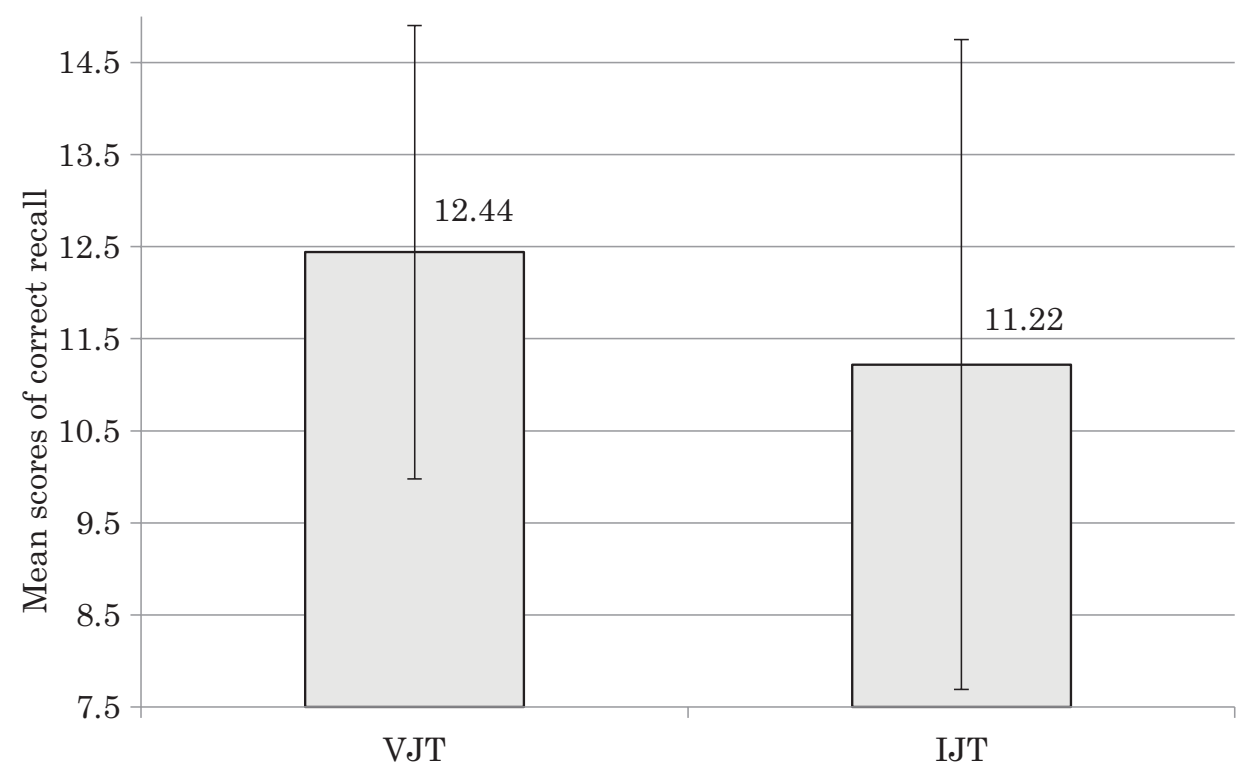

Figure 1. The Recall Performances of Two Tasks Are Graphed. 
A further implication can be drawn from Experiment B. Since EmInvSemProc yielded a better result than imaging-involved semantic processing, it can be argued that emotion involvement may be as important as (or, more important than) imaging involvement, contrary to the claims of TFA (Nation \& Webb, 2011). Unlike imaging involvement, emotion involvement is not explicitly included in such an influential criterion as TFA. The present studies showed that involvement of micro-level emotion, if harnessed actively and optimally, can be a powerful cognitive aid for successful learning and should not be overlooked. ${ }^{3}$

One of the limitations of the studies concerns the methodology. Due to the adaptation of a traditional hypothetico-deductive experimental psychological research paradigm, there was insufficient pedagogical contrivance. Moreover, the dynamic systems, in which emotion and cognition are reciprocally influencing each other, were not fully investigated. This lack of ecological validity, however, may imply that the full potential of the technique has yet to be revealed. If pedagogic activities are developed to enhance EmInvSemProc in the classroom, the technique may yield better results. The open question for further studies then is as follows: how can micro-level emotion be incorporated and operationalized optimally in pedagogical practices?

\section{Conclusion}

It has been proposed and verified that micro-level emotion affects L2 lexical learning and acquisition. The new ontological emphasis of SLA studies should be "the mutual entailment of the cognitive, the social, and the emotional" factors (The Douglas Fir Group, 2016, p. 21), not just cognitive-socioemotional factors. To borrow from Barrett (2012), "emotions are, at the same time, socially constructed and biologically evident," (p. 413) and it is a pressing issue to "explicitly theorize about how to integrate physical, mental, and social levels" (p. 424). As the author has once written in a paper, "if such a micro-level elusive subconscious dynamism of emotion is depreciated and foreclosed from mindful consideration, it may well be metaphorically described that we are overlooking the Blue Bird, which has long been right in front of our eyes, waiting to be found and cherished" (Kanazawa, 2016a, p. 27).

\section{Notes}

1. Emotional valence was another target of inquiry in the experiment, which is beyond the scope of this paper (cf. Kanazawa, 2016c).

2. The single difference of the two tasks in TFA concerns the following criterion: [No. 17] Does the activity involve imaging?

3. A constructive proposition to TFA would be to add the following criterion: [No. 19] Does the activity employ Emotion-Involved Processing?

\section{References}

American Psychological Association. (2010). American Psychological Association ethical principles of psychologists and code of conduct. Retrieved from http:// www.apa.org/ethics/code/ 
Barcroft, J. (2015). Lexical input processing and vocabulary learning. Amsterdam, The Netherlands: John Benjamins.

Barrett, L.F. (2012). Emotions are real. Emotion, 12(3), 413-429. doi:10.1037/ a0027555

Bergson, H. (1911). Matière et mémoire [Matter and memory]. (N. Paul \& W. Palmer, Trans.). London, England: George Allen and Unwin. (Original work published 1896).

Ciompi, L., \& Panksepp, J. (2005). Energetic effects of emotions on cognitions. In R. Ellis \& N. Newton (Eds.), Consciousness and emotion (pp. 23-55). Amsterdam, The Netherlands: John Benjamins.

Craik, F.I.M., \& Lockhart, R. (1972). Levels of processing: A framework for memory research. Journal of Verbal Learning and Behavior, 11, 671-681. doi:10.1016/S0022-5371(72)80001-X

Damasio, A.R. (2003). Looking for Spinoza: Joy, sorrow, and the feeling brain. London, England: William Heinemann.

Dewaele, J.-M., \& MacIntyre, P.D. (2016). Foreign language enjoyment and foreign language classroom anxiety: The right and left feel of the language learner. In P.D. MacIntyre, T. Gregersen, \& S. Mercer (Eds.), Positive psychology in $S L A$ (pp. 215-236). Bristol, England: Multilingual Matters.

Dörnyei, Z., Henry, A., \& Muir, C. (2016). Motivational currents in language learning: Frameworks for focused interventions. New York, NY: Routledge.

Dörnyei, Z., \& Ushioda, E. (2011). Teaching and researching motivation (2nd ed.). Harlow, England: Pearson Education.

Garrison, D.R., Anderson, T., \& Archer, W. (1999). Critical inquiry in a text-based environment: Computer conferencing in higher education. The Internet Higher Education, 2(2), 87-105. doi:10.1016/S1096-7516(00)00016-6

Gregersen, T.S., \& MacIntyre, P.D. (2017). Idiodynamics: An innovative method to build emotional intelligence through systematic self-assessment/reflection/critique. In T.S. Gregersen \& P.D. MacIntyre (Eds.), Innovative practices in language teacher education: Spanning the spectrum from intra- to interpersonal professional development (pp. 33-54). Gewerbestrasse, Switzerland: Springer.

Kanazawa, Y. (2015). Do listening and oral reading of visually presented English words affect implicit lexical recognition memory?: An empirical study with Japanese learners of English. Annual Review of English Language Education in Japan, 26, 141-156.

Kanazawa, Y. (2016a). Micro-level emotion as a factor of L2 vocabulary memory: The effect of lexical emotional valence on incidental recall performance. Language Education \& Technology, 53, 23-52.

Kanazawa, Y. (2016b, September). The more emotionally intelligent, the more likely to remember words without elicited emotional elaboration: A possible individual difference in L2 lexical retention. Paper presented at the Vocab@Tokyo International Conference on Vocabulary Acquisition, Meiji Gakuin University, Tokyo, Japan. doi:10.13140/RG.2.2.33696.17920 
Kanazawa, Y. (2016c, September). “Don't just think, but also feel.” Paper presented at the Pacific Second Language Research Forum 2016 (PacSLRF2016), Chuo University, Tokyo, Japan.

King, K.A., \& Mackey, A. (2016). Research methodology in second language studies: Trends, concerns, and new directions. The Modern Language Journal, 100(Suppl.), 219-227. doi:10.1111/mod1.12309

Laufer, B., \& Hulstijn, J.H. (2001). Incidental vocabulary acquisition in a second language: The construct of task-induced involvement. Applied Linguistics, 22(1), 1-26. doi:10.1093/applin/22.1.1

LeDoux, J. (2012). Rethinking the emotional brain. Neuron, 73, 653-676. doi:10.1016/j.neuron.2012.02.004

Miyahara, M. (2015). Emerging self-identities and emotion in foreign language learning. Bristol, England: Multilingual Matters.

Morris, C.D., Bransford, J.D., \& Franks, J.J. (1977). Levels of processing versus transfer appropriate processing. Journal of Verbal Learning and Verbal Behavior, 16, 519-533. doi:10.1016/S0022-5371(77)80016-9

Nation, P. (2015, November). Recent research in vocabulary learning. Lecture given at the 41st Annual International Conference on Language Teaching and Learning \& Educational Materials Exhibition (JALT2015), Shizuoka, Japan.

Nation, P., \& Webb, S. (2011). Researching and analyzing vocabulary. Boston, MA: Heinle.

Pavlenko, A. (2013). The affective turn in SLA. In D. Gabryś-Barker \& J. Bielska (Eds.), The affective dimension in second language acquisition (pp. 3-28). Bristol, England: Multilingual Matters.

Peirce, C.S. (1931). The categories in detail. In C. Hartshorne \& P. Weiss (Eds.), Collected papers of Charles Sanders Peirce (Vols. 1-2; Paras. 1.300-1.321). Cambridge, MA: Harvard University Press. (Original draft written 1894).

Prior, M.T., \& Kasper, G. (2016). Emotion in multilingual interaction. Amsterdam, The Netherlands: John Benjamins.

Sharwood Smith, M. \& Truscott, J. (2014). Multilingual mind: A modular processing perspective. Cambridge, England: Cambridge University Press.

Schmitt, N. (2010). Researching vocabulary: A vocabulary research manual. Basingstoke, England: Palgrave Macmillan.

Schütze, U. (2017). Language learning and the brain: Lexical processing in second language acquisition. Cambridge, England: Cambridge University Press.

The Douglas Fir Group. (2016). A transdisciplinary framework for SLA in a multilingual world. The Modern Language Journal, 100(Suppl.), 19-47. doi:10.1111/modl.12301

van Lier, L. (2004). The ecology and semiotics of language learning: A sociocultural perspective. Norwell, MA: Kluwer Academic.

Whitehead, A.N. (1978). Process and reality. New York, NY: The Free Press. (Original work published 1929). 